\title{
Forns index as a useful noninvasive predictor of esophageal varices in liver cirrhosis
}

\author{
Rizqi Arini Siregar*, Leonardo B. Dairi*, and Gontar Alamsyah Siregar*
}

\begin{abstract}
\section{BACKGROUND}

Rupture and bleeding from esophageal varices are major complications of portal hypertension and associated with a high mortality rate. Noninvasive serum markers of liver fibrosis could be used as predictors of esophageal varices in cirrhotic patients. The objective of this study was to assess the performance of Forns index as a noninvasive predictor in diagnosing esophageal varices.
\end{abstract}

\section{METHODS}

A cross-sectional study was done in 51 cirrhotic patients who were admitted to Adam Malik hospital, Medan. Demographic and clinical data were recorded and laboratory tests were performed, so that Forns index could be calculated. The difference between Forns index and size of esophageal varices as determined by endoscopy was tested by independent$\mathrm{t}$ and Mann-Whitney analysis. The diagnostic performance was assessed using sensitivity, specificity, positive predictive value (PPV), negative predictive value (NPV), accuracy, likelihood ratios and areas under the receiver operating characteristic curves (AUROC).

\section{RESULTS}

Of the 51 patients with esophageal varices included in this study, the size of esophageal varices comprised F2 (37.3\%), F3 (33.3), and F1 (29.4\%). Most patients were of Child-Plug $\mathrm{C}$ type $(52.6 \%)$. There was a significant difference between Forns index and grade of esophageal varices. The AUROC for Forns index was 0.717 (95\% CI: $0.561-0.872$ ) and the cutoff $>7.92$ was highly predictive to diagnose large esophageal varices with a sensitivity of $63.9 \%$, specificity of $73.3 \%$, PPV of $85.2 \%$, NPV of $45.8 \%$ and accuracy of $71.7 \%$.

\section{CONCLUSION}

Forns index was significantly increased in large esophageal varices. Forns index is a good noninvasive predictor of esophageal varices in cirrhotic patients.

Keywords: Forns index, non-invasive parameter,esophageal varices, cirrhotic patients
*Division of Gastroenterohepatology, Department of Internal Medicine, Faculty of Medicine, University of Sumatera Utara, Medan

Correspondence:

dr. Rizqi Arini Siregar Division of Gastroenterohepatology, Department of Internal Medicine, Faculty of Medicine,

University of Sumatera Utara Jl. Bunga Lau No.17 Medan Sumatera Utara 20136

Fax: +6261 8363009 Mobile: +62813 70433555

Email: arini_siregar@yahoo.com

Univ Med 2016;35:199-205

DOI: 10.18051/UnivMed.2016.v35.199-205 pISSN: 1907-3062 / eISSN: 2407-2230

This open access article is distributed under a Creative Commons Attribution-Non Commercial-Share Alike 4.0 International License 


\section{INTRODUCTION}

Cirrhosis, the end stage of chronic liver disease, is the most common cause of portal hypertension. ${ }^{(1)}$ Esophageal varices is a major complication that frequently appears in more than $90 \%$ of liver cirrhosis patients. Among diagnosed cases of liver cirrhosis, about $60 \%$ have some degree of esophageal varices. ${ }^{(2)}$ The mortality at each bleeding episode is between $10-20 \%$. ${ }^{(3)}$ One-year survival is only about $63 \% .^{(4)}$

In cirrhotic patients, screening for esophageal varices is highly recommended and extremely important because it is closely linked to the scheme of nonselective betablocker therapy or endoscopic prophylaxis to prevent variceal bleeding. ${ }^{(5)}$ The current screening method is endoscopy, which is performed every 2 to 3 years in patients without esophageal varices, every 1 to 2 years in those with mild varices, and annually in those with decompensated cirrhosis. However, periodical endoscopic checkup is extremely expensive and frequently associated with complications such as bleeding and perforation. In addition, not every kind of health service has endoscopic facilities, along with the limitation of competition to do the endoscopic checkup. Therefore there is a need in relation to portal hypertension for a noninvasive checkup procedure that can identify the presence of esophageal varices in patient with liver cirrhosis. ${ }^{(6)}$

Some noninvasive methods have been proposed to serve as markers for evaluating the degree of liver fibrosis and esophageal varices, including serum markers, such as aspartate aminotransferase (AST) to platelet ratio index (APRI), FIB-4, Forns index and Lok score, ${ }^{(7-9)}$ transient elastography, ${ }^{(10)}$ magnetic resonance elastography ${ }^{(1)}$ and acoustic radiation force impulse imaging. ${ }^{(12,13)}$

Common tests previously validated as predictors of liver fibrosis, such as aspartate aminotransferase-to-platelet ratio (APRI), aspartate aminotransferase-to-alanine aminotransferase ratio (AAR), FIB-4, FI, King, Lok, Forns, and Fibro index scores, are primarily based on regular laboratory tests and readily available demographic data, and do not need any special experience in imaging techniques. ${ }^{(14,15)}$ They are more convenient and economical in clinical practices.

Forns index is a serum biomarker that is used to predict liver fibrosis and is predicted to be able to replace liver biopsy or endoscopy in detecting esophageal varices. Forns index is based on the variables of platelet count, age, gamma GT, and total cholesterol. Some studies suggest that there is a relationship between liver fibrosis, portal hypertension, and esophageal varices, whereas other studies are trying to carry out research about Forns index in predicting esophageal varices. ${ }^{(7)}$ Based on the above, the objective of this study was to determine the association of esophageal varices and Forns index and the diagnostic accuracy of Forns index in liver cirrhosis patients.

\section{METHODS}

\section{Research design}

A cross-sectional study was conducted on patients with liver cirrhosis at Adam Malik hospital, Medan, from September to December 2014.

\section{Research subjects}

Males or females aged $\geq 18$ years, having liver cirrhosis, and agreeing to sign informed consent, were included in this study. Patients who previously had variceal bleeding, endoscopic therapy (ligation or sclerotherapy), surgical treatment for portal hypertension (transjugular intrahepatic portosystemic shunt, TIPS), or were on beta blocker treatment, were excluded from the study.

The formula used to calculate the sample size for hypothesis testing was:

$\mathrm{n}=\frac{\left(\mathrm{Z}_{(1-\alpha / 2} \sqrt{\mathrm{P}_{\mathrm{o}}\left(1-\mathrm{P}_{\mathrm{o}}\right)}+\mathrm{Z}_{(1-\beta)} \sqrt{\mathrm{P}_{\mathrm{a}}\left(1-\mathrm{P}_{\mathrm{a}}\right)}\right)^{2}}{\left(\mathrm{P}_{\mathrm{o}}-\mathrm{P}_{\mathrm{a}}\right)^{2}}$ 
where:

$\mathrm{Z}(1-\alpha / 2)=$ raw deviate of alpha, for $\alpha=0.05$

$\rightarrow \mathrm{Z}(1-\alpha / 2)=1.96$

$\mathrm{Z}(1-\beta)=$ raw deviate of beta, for $\beta=0.10 \rightarrow$

$Z(1-\beta)=1.282$

$\mathrm{P}_{0}-\mathrm{Pa}=$ significant difference in proportions $=$ 0.15

$\mathrm{P}_{0}=$ proportion of liver cirrhosis cases at a number of hospitals in Indonesia $\rightarrow 3.5 \%=0.035$

$\mathrm{Pa}=$ estimated proportion of liver cirrhosis cases under study $=0.185$

Minimal sample size $=33$ persons per group

The subjects' personal history was assessed through anamnesis and physical checkup, radiological checkup, laboratory checkup consisting of determination of platelet count, gamma-glutamyl transferase (gamma GT) concentration, and total cholesterol concentration, and endoscopic checkup.

Esophageal varices were classified into three types: F1 (small straight esophageal varices), F2 (slightly enlarged tortuous esophageal varices occupying less than one-third of the esophageal lumen), and F3 (large coilshaped esophageal varices occupying more than one-third of the esophageal lumen). ${ }^{(16)}$

\section{Serum biochemical markers}

Venous blood samples were taken from all participants after an overnight fast (8-12 hours). The samples were tested in the laboratory to determine aspartate aminotransferase (AST) and alanine aminotransferase (ALT) levels, gammaglutamyl transferase (gamma GT), total cholesterol and platelet (PLT) count. To assess the gamma GT level we used a kinetic assay with (gamma-L-glutamyl)-p-nitroanilide and glycylglycine as substrates. To assess total cholesterol we used R1 reagents and the Cobas Mira® automatic analyzer.

\section{Forns index}

The formula used to calculate the Forns index was $7.811-3.131 \mathrm{x} \ln$ [platelet count $\left(10^{9} /\right.$ L) $]+0.781 \times \ln [$ gamma GT(IU/L) $]+3.467 \times \ln$ [age (years)] $-0.014 \times$ [cholesterol $(\mathrm{mg} / \mathrm{dL}) .{ }^{(17)}$

\section{Data analysis}

To display a descriptive overview of the patients' basic data a tabulation system was used. The independent t-test was used for normally distributed data, and Mann Whitney test for nonnormally distributed data. Statistical analysis was performed using SPSS with significance limit of $p<0.05$. To obtain the cut-off points for Forns index, the area under the receiver operating characteristic curve (AUROC) was used. In this study, we also performed diagnostic tests to obtain the sensitivity, specificity, positive predictive value (PPV), negative predictive value (NPV), likelihood ratio for positive tests $(\mathrm{LR}+)$, likelihood ratio for negative tests (LR -), and accuracy (Acc).

To evaluate the severity of liver cirrhosis we used the Child Pugh score:

\begin{tabular}{|l|c|c|c|}
\hline \multirow{2}{*}{} & \multicolumn{3}{|c|}{ Points } \\
\cline { 2 - 4 } & 1 & 2 & 3 \\
\hline Encephalopathy & None & $\begin{array}{c}\text { Grade 1-2 } \\
\text { (or precipitant induced) } \\
\text { Mild to moderate } \\
\text { (diuretic responsive) }\end{array}$ & $\begin{array}{c}\text { Grade 3-4 } \\
\text { (or chronic) }\end{array}$ \\
\hline Ascites & None & $2-3$ & $\begin{array}{c}\text { Severe } \\
\text { (diuretic refractory) }\end{array}$ \\
\hline Bilirubin $(\mathrm{mg} / \mathrm{dL})$ & $<2$ & $2.8-3.5$ & $>3$ \\
\hline Albumin $(\mathrm{g} / \mathrm{dL})$ & $>3.5$ & $1.7-2.3$ & $>2.8$ \\
\hline INR & $<1.7$ & & $>2.3$ \\
\hline "Child-Turcotte-Pugh Class obtained by adding score for each parameter (total points)
\end{tabular}




\section{Ethical clearance}

Ethical clearance (permission to carry out research) was obtained from the Health Sector Research Committee of the Faculty of Medicine, University of North Sumatra.

\section{RESULTS}

In this study, the total number of participants consisted of 51 patients with liver cirrhosis who had met the inclusion criteria. Most patients were male (34 persons or $66.7 \%$ ). The mean age of the patients involved in this study was $52.04 \pm 12.33$ years. Respondents with hepatitis B comprised 30 persons (58.8\%), hepatitis C 2 persons (3.9\%),

Table 1. Distribution of demographic characteristics of respondents $(n=51)$

\begin{tabular}{|c|c|}
\hline Parameter & $\begin{array}{c}\text { Mean } \pm \text { SD, } \\
\text { (min-max) } \\
\text { or n }(\%)\end{array}$ \\
\hline \multicolumn{2}{|l|}{ Gender } \\
\hline Male & $34(66.7)$ \\
\hline Fernale & $17(33.3)$ \\
\hline Age (years) & $52.04 \pm 12.33$ \\
\hline Platelet $\left(x 10^{y} / L\right)$ & $104(31-144)$ \\
\hline $\mathrm{AST}(\mathrm{U} / \mathrm{L})$ & $56(18-567)$ \\
\hline $\mathrm{ALT}(\mathrm{U} / \mathrm{L})$ & $38(13-233)$ \\
\hline GammaGT (U/L) & $66(6-530)$ \\
\hline Total bilirubin (mg/d $)$ & $1.63(0.25-1497)$ \\
\hline Total chol ester ol (m gdL) & $149.12 \pm 6755$ \\
\hline Albumin $\left(g^{\prime} d \mathbb{L}\right)$ & $2.5 \pm 0.75$ \\
\hline FT (seconds) & $2.7(0.1-20.6)$ \\
\hline INR & $1.36(0.92-1481)$ \\
\hline \multicolumn{2}{|l|}{ Ascites } \\
\hline None & $12(23.5)$ \\
\hline Minimum & $8(15.7)$ \\
\hline Medium & $23(45.1)$ \\
\hline Maximum & $8(15.7)$ \\
\hline \multicolumn{2}{|l|}{ Chil dPugh } \\
\hline A & $10(13.2)$ \\
\hline $\mathrm{B}$ & $26(34.2)$ \\
\hline $\mathrm{C}$ & $40(52.6)$ \\
\hline \multicolumn{2}{|l|}{ Liver cirthosis etiology } \\
\hline Hep atitis B & $30(58.8)$ \\
\hline Hep atitis $\mathrm{C}$ & $2(3.9)$ \\
\hline Negative & $19(37.3)$ \\
\hline Forns index & $7.85 \pm 2.43$ \\
\hline \multicolumn{2}{|l|}{ Esophageal vati ces grade } \\
\hline Stmall esophageal varices (F1) & $15(29.4)$ \\
\hline Large esophageal varices & $36(70.6)$ \\
\hline $\mathrm{F} 2$ & $19(37.3)$ \\
\hline F3 & $17(33.3)$ \\
\hline
\end{tabular}

while those with a negative result for hepatitis B or $\mathrm{C}$ comprised 19 persons (37.3\%). Respondents with Child Pugh A consisted of 10 persons (13.2\%), with Child Pugh B 26 persons (34.2\%), and Child Pugh C 40 persons (52.6\%). The medians of platelet count and gamma GT of the patients in this study were respectively 104 (31144) $\times 10^{9} / \mathrm{L}$ and 66 (6-530) U/L, while mean total cholesterol was $149.12 \pm 67.55 \mathrm{mg} / \mathrm{dL}$. Regarding the size of the esophageal varices, which were graded based on endoscopic checkup results, there were esophageal varices of $F 1$ size in 15 people (29.4\%), F2 size in 19 people (37.3\%), and F3 size in 17 people (33.3\%) (Table 1).

There was a significant difference in mean Forns index between large esophageal varices and small esophageal varices, with the Forns index of large esophageal varices $(8.47 \pm 2.05)$ being significantly higher than that of the small esophageal varices $(6.37 \pm 2.68)(\mathrm{p}=0.016)$ (Table 2).

From the receiver operating characteristics (ROC) curve, the best Forns index cut off value was determined to be 7.92. The Forns index value of > 7.92 in the diagnosis of large sized esophageal varices had the following characteristics: sensitivity $63.9 \%$, specificity $73.3 \%$, PPV $85.2 \%$, NPV $45.8 \%$, LR (+) 2.4, LR (-) 0.49, and diagnostic accuracy $71.7 \%$ (Figure 1).

\section{DISCUSSION}

Among the 51 study subjects, the most common cause of liver cirrhosis $(58.8 \%)$ was hepatitis B infection. This agrees with the study conducted by Limquiaco et al, ${ }^{(18)}$ where the most common cause of liver cirrhosis was chronic hepatitis B (40\%) infection. However, different results were found in a US study showing hepatitis $\mathrm{C}$ virus (HCV) infection and alcohol abuse to be the two leading causes of liver cirrhosis. ${ }^{(19)}$ This was also the case with the report of Stefanescu et al., ${ }^{(7)}$ where the most common cause of liver cirrhosis $(49.78 \%)$ was chronic hepatitis $\mathrm{C}$ infection. These differences may caused by different research locations, since 
Table 2. Difference in biochemical characteristics between small and large esophageal varices

\begin{tabular}{|c|c|c|c|}
\hline \multirow{2}{*}{ Characteristic } & \multicolumn{2}{|c|}{ Esophage al varies } & \multirow[b]{2}{*}{$\mathbf{p}$} \\
\hline & Small & $L$ arge & \\
\hline Age (years) (a) & $56.47 \pm 14.78$ & $50.19 \pm 10.85$ & 0.098 \\
\hline Platelet $\left(x 10^{y} / L\right)^{(b)}$ & $200.20 \pm 131.54$ & $107.14 \pm 61.15$ & $0.005 *$ \\
\hline Total bilinubin $(\mathrm{m} g / \mathrm{dL})^{(\mathrm{b})}$ & $3.56 \pm 4.01$ & $2.26 \pm 1.91$ & 0.563 \\
\hline Total cholester ol $\left(\mathrm{m} g(\mathbb{d})^{(a)}\right.$ & $182.53 \pm 98.68$ & $135.17 \pm 44.1$ & 0.200 \\
\hline Gamma GT $(\mathrm{U} / \mathrm{T})^{(\mathrm{b})}$ & $126.4 \pm 147.80$ & $105.03 \pm 103.34$ & 0.975 \\
\hline AST(U/L) $)^{(b)}$ & $110.67 \pm 142.93$ & $77.42 \pm 67.81$ & 0.694 \\
\hline Albumin $(g / d L)^{(a)}$ & $2.55 \pm 0.73$ & $2.53 \pm 0.77$ & 0.935 \\
\hline $\mathrm{PT}\left(\right.$ seconds) ${ }^{101}$ & $4.43 \pm 5.17$ & $3.66 \pm 2.59$ & 0.812 \\
\hline $\mathrm{INR}^{(0)}$ & $2.26 \pm 3.49$ & $1.47 \pm 0.32$ & 0.374 \\
\hline $\mathrm{ALT}(\mathrm{U} / \mathrm{L})^{(\mathrm{a})}$ & $59.67 \pm 59.36$ & $49.78 \pm 39.27$ & 0.975 \\
\hline Forns index ${ }^{(b)}$ & $6.37 \pm 2.68$ & $8.47 \pm 2.05$ & $0.016^{*}$ \\
\hline
\end{tabular}

(a) Independent t-test ${ }^{(\mathrm{b})}$ Mann Whitney test; *Significant; *AST: Aspartate aminotransferase; ALT: Alanine aminotransferase; PT: protrombin time ;INR: international normalized ratio

the hepatitis C prevalence is higher in Europe and the US.

For the Child Pugh classification, Limquiaco et al. ${ }^{(18)}$ mention that Child A accounted for 3\%, Child B for $73 \%$, and Child C for 23\%. Stefanescu et al. ${ }^{(7)}$ found values of $75.9 \%, 18.4 \%$, and $5.7 \%$ for Child A, Child B and Child C, respectively. In our study we found that Child A comprised 13.2\%, Child B 34.2\%, and Child C 52.6\%. The high prevalence of Child $\mathrm{C}$ in this study was due to its being conducted at a referral hospital, since most of the patients referred to this institution had advanced disease. Our study showed that the proportion of esophageal varices for F1, F2, and F3 was $29.4 \%, 37.3 \%$, and $33.3 \%$, respectively. A previous study on 40 subjects showed that the proportion of esophageal varices for F1, F2, and F3 was $32.5 \%, 42.5 \%$ and $25.0 \%$, respectively. ${ }^{(20)}$

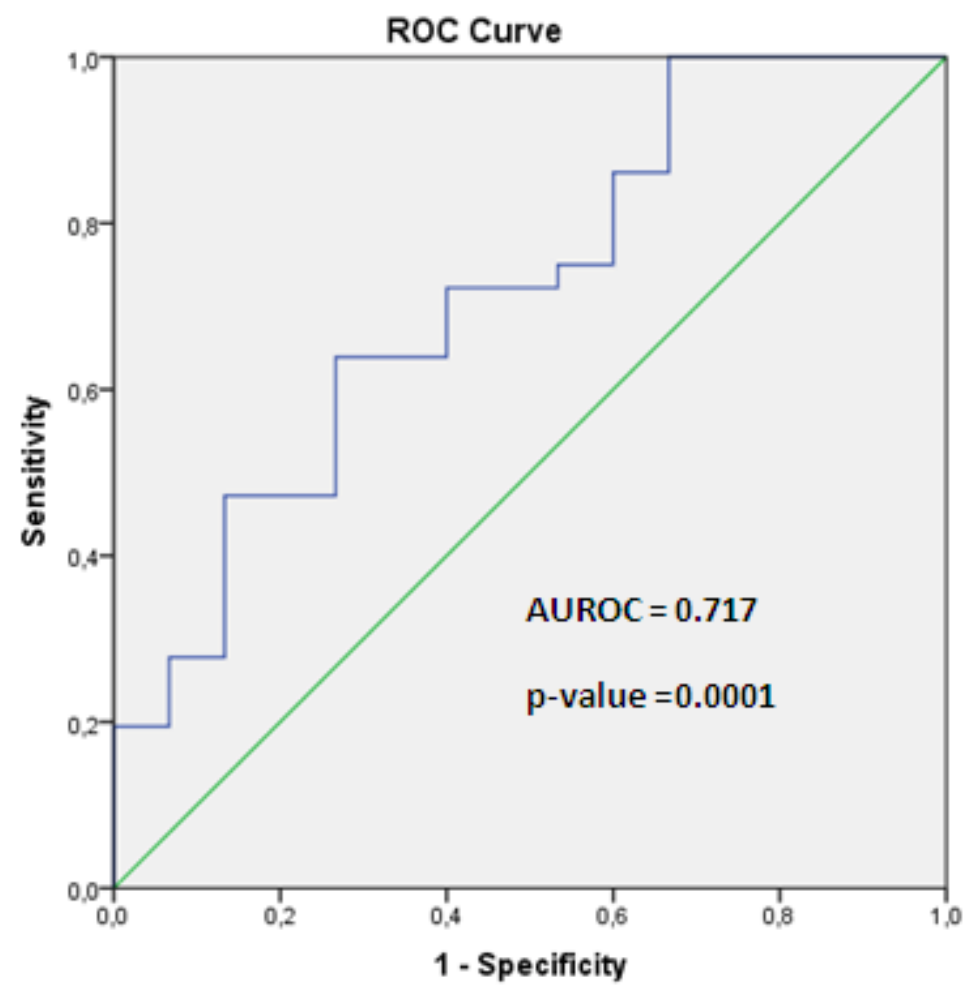

Figure 1. Forns index ROC in predicting the grade of varices 
Mild to moderate thrombocytopenia occurs in $49-64 \%$ of patients with liver cirrhosis. The etiology of thrombocytopenia is multifactorial, including increased platelet sequestration in the spleen in congestive splenomegaly, which is caused by portal hypertention, decreased production of thrombopoietin, as well as platelet destruction as a result of immune processes or antibodies. ${ }^{(21)}$ There was a significant difference in mean platelet count between the group of large esophageal varices and the group of small esophageal varices, with a significantly lower mean platelet count among large esophageal varices as compared with small esophageal varices. This is in line with a previous study reporting that low platelet count was an independent risk factor or predictor for the presence of esophageal varices and their size. ${ }^{(22)}$

The study conducted by Stefanescu et al. ${ }^{(7)}$ evaluated four non-invasive methods that had previously been known as predictors of liver fibrosis grade, for identifying esophageal varices and their size, in comparison with endoscopic checkup as a standard procedure. One of the evaluated methods was Forns index. These investigators found that the latter method can be a predictor of the presence of esophageal varices, particularly those of the larger sizes. In their study the investigators found that for detecting esophageal varices of any size, Forns index (cutoff > 7.297) had an AUROC of 0.648, whereas in detecting large sized esophageal varices, Forns index (cut-off > 8.538) had an AUROC of 0.645. However, this is the disadvantage of using serum markers of liver fibrosis, in which the variables used in calculating a non-specific score describing liver abnormalities, can be affected by other disease conditions of the patients.

The present study had different cut-off values for diagnosing large esophageal varices as compared to the study results of Stefanescu et al. ${ }^{(7)}$ We found that the lower cut-off value of $>7.92$ in the present study may be affected by different mean variable values included in the Forns index valuation, such as the younger age of the study sample, lower mean gamma GT, and higher mean platelet count than that reported in the study by Stefanescu et al. ${ }^{(7)}$ Moreover, there is a difference in sample size which may be a limitation of our study, since our sample was much smaller than that of the study of Stefanescu et al., ${ }^{(7)}$ which involved 231 persons.

The predictive value of the Forns index cufoff value of $>7.92$ in diagnosing large esophageal varices, having $63.9 \%$ sensitivity, $73.3 \%$ specificity, $85.2 \% \mathrm{PPV}, 45.8 \% \mathrm{NPV}$, and an accuracy of up to $71.7 \%$, can be used as one of the noninvasive methods of choice for detection of esophageal varices. In addition, Forns index is expected to be used as a basis in giving â-blocker treatment as a primary prevention against the limitation of a physician's competence to perform endoscopic checkup. ${ }^{(1)}$

\section{CONCLUSION}

This study found a correlation between the grade of esophageal varices and Forns index in liver cirrhosis patients. Forns index is a noninvasive parameter that can be used to predict the grade of esophageal varices in cirrhotic patients.

\section{CONFLICT OF INTEREST}

The authors state that there are no conflicts of interest with regard to this manuscript.

\section{ACKNOWLEDGEMENT}

We thank all study subjects who agreed to participate in the present study and all colleagues who gave their advice to improve the manuscript.

\section{REFERENCES}

1. Biecker E. Portal hypertension and gastrointestinal bleeding: diagnosis, prevention and management. World J Gastroenterol 2013; 19:5035-50.

2. Ashkenazi E, Kovalev Y, Zuckerman E. Evaluation and treatment of esophageal varices in the cirrhotic patient. IMAJ 2013;15:109-15.

3. Turon F, Casu S, Hernandez-Gea V, et al. Variceal and other portal hypertension related 
bleeding. Best Pract Res Clin Gastroenterol 2013;27:649-64.

4. Stokkeland K, Brandt L, Ekbom A, et al. Improved prognosis for patients hospitalized with esophageal varices in Sweden 1969-2002. Hepatology 2006;43:500-5.

5. De Franchis R. Evolving consensus in portal hypertension. Report of the Baveno IV consensus workshop on methodology of diagnosis and therapy in portal hypertension. J Hepatol 2005; 43:167-76.

6. De Franchis R. Revising consensus in portal hypertension: report of the Baveno $\mathrm{V}$ consensus workshop on methodology of diagnosis and therapy in portal hypertension. J Hepatol 2010;53:762-8.

7. Stefanescu H, Grigorescu M, Lupsor M, et al. A new and simple algorithm for the noninvasive assessment of esophageal varices in cirrhotic patients using serum fibrosis markers and transient elastography. J Gastrointestin Liver Dis 2011;20:57-64.

8. Friedrich-Rust M, Wunder K, Kriener S, et al. Liver fibrosis in viral hepatitis: noninvasive assessment with acoustic radiation force impulse imaging versus transient elastography. Radiology 2009;252:595-604.

9. Garcia-Tsao G, Sanyal AJ, Grace ND, Carey W and the Practice Guidelines Committee of the American Association for the Study of Liver Diseases, the Practice Parameters Committee of the American College of Gastroenterology. Prevention and management of gastroesophageal varices and variceal hemorrhage in cirrhosis. Hepatology 2007;46:922-38.

10. Friedrich-Rust M, Ong MF, Martens S, et al. Performance of transient elastography for the staging of liver fibrosis: a meta-analysis. Gastroenterology 2008;134:960-974.

11. Talwalkar JA, Yin M, Venkatesh S, et al. Feasibility of in vivo MR elastographic splenic stiffness measurements in the assessment of portal hypertension. Am J Roentgenol 2009;193: 122-7.

12. Grgurevic I, Cikara I, Horvat J, et al. Noninvasive assessment of liver fibrosis with acoustic radiation force impulse imaging: increased liver and splenic stiffness in patients with liver fibrosis and cirrhosis. Ultraschall Med 2011;32:160-6.
13. Bota S, Sporea I, Sirli R, et al. Spleen assessment by acoustic radiation force impulse elastography (AFRI) for prediction of liver cirrhosis and portal hypertension. Med Ultrason 2010;12:213-7.

14. Vallet-Pichard A, Mallet V, Nalpas B, et al. FIB4: an inexpensive and accurate marker of fibrosis in HCV infection: comparison with liver biopsy and fibrotest. Hepatology 2007;46:32-6.

15. Cross TJ, Calvaruso V, Maimone S, et al. Prospective comparison of Fibroscan, King's score and liver biopsy for the assessment of cirrhosis in chronic hepatitis $\mathrm{C}$ infection. J Viral Hepat 2010;17:546-54.

16. Farber E, Fischer D, Eliakim R, et al. Esophageal varices: evaluation with esophagography with barium versus endoscopic gastroduodenoscopy in patients with compensated cirrhosis-blinded prospective study. Radiology 2005;237:535-40.

17. Forns X, Ampurdanes S, Llovet JM, et al. Identification of chronic hepatitis $\mathrm{C}$ patients without hepatic fibrosis by a simple predictive model. Hepatology 2002;36:986-92.

18. Limquiaco J, Daez R, Gloria Rr, et al. Clinical predictors of bleeding from esophageal varices: a retrospective study. Phil J of Gastroenterology 2006;2:103-11.

19. Shoreibah M, Anand BS, Singal AK. Alcoholic hepatitis and concomitant hepatitis $\mathrm{C}$ virus infection. World J Gastroenterol 2014;20:1192934.

20. Mifune H, Akaki S, Ida K, et al. Evaluation of esophageal varices by multidetector-row CT: correlation with endoscopic red color sign. Acta Med Okayama 2007;61:247-54.

21. Sebastiani G, Tempesta D, Fattovich G, et al. Prediction of oesophageal varices in hepatic cirrhosis by simple serum noninvasive markers: results of a multicenter, large-scale study. J Hepatol 2010;53:630-8.

22. Suk TK. Revision and update on clinical practice guideline for liver cirrhosis. The Korean J Hepatol 2012;18:1-21. 